\title{
ROLE OF COVID AS A CATALYST IN INCREASING ADOPTION OF OTTS IN INDIA: A STUDY OF EVOLVING CONSUMER CONSUMPTION PATTERNS AND FUTURE BUSINESS SCOPE
}

\author{
Garima Sharma Nijhawan \\ PhD scholar, Manav Rachna Institute of International Research and \\ GuestAsst. Professor at Delhi School of Journalism, Delhi University \\ Prof. (Dr.) Surbhi Dahiya \\ Professor and Course Director, Department of English Journalism \\ Indian Institute of Mass Communication, New Delhi
}

\begin{abstract}
COVID-19 is an unprecedented global pandemic which has changed the way audience consume media. An undeniable trend surfaced in this period-adoption of OTTs. There are many reports which point to the growing market and consumer appetite for content of choice available on OTT platforms. OTTs offer a never before consumer advantage- choice of content, ease of access, choice of device / mediums (hand phone, laptop, tablet or TV screen). Gone are the days when family members fought for screen time of choice on family's singular home device i.e. TV. With this study, the researchers studied the evolution of OTT space in India and reviewed the dynamic OTT space - evaluate some firsts like big banner movie releases on platforms like Amazon and Netflix, return of old content like Mythological programmes from the DD era on Hotstar etc. To complete the study, it was imperative to evaluate the impact of growing content consumption on psychographics across generations (children, adults and elderlies) as there is limited censorship in the OTT space. With this background, the researchers workedon the objectives and tried to evaluate the role played by the pandemic in evolving OTT media consumption trends; a qualitative mapping of increase in OTT adoption - Pre and Post COVID 19 in India; study underlying trends around increasing consumer appetite for the medium and analyse psychographic impact on children, adults and elderlies - listing pros and cons for freely available content with minimal censorship. The researchers adopteda combined qualitative and quantitative approach to extrapolate the data. A survey was also conducted to do audience mapping and analysis.In addition to primary data, content from news articles, industry research reports, international journals for accumulation of key trends were analysed.
\end{abstract}

Keywords: Digital media, COVID-19, OTT platforms, mobile media, viewership and lockdown

\section{INTRODUCTION}

The news media and general entertainment sector in the country has evolved dynamically over the past 10 years and more after the internet boom. Entry and uptake of OTT (Over-the-top) players has changed the way we consume content and as per an industry report by a credible and global marketing research firm - The Boston Consulting Group( BCG) titled 'Entertainment Goes Online', OTT content market in India is pegged to reach \$5 billion in size by 2023.1 There are multiple factors which have fuelled this rapid growth and the unfortunate health pandemic COVID19 has proved beneficial for OTT players in the past six months. Some additional factors which have contributed to this growth include rising house hold income, growing exposure to international trends, increased incidence of travel for leisure and business, internet adoption in tier II and III markets, acceptance of content and a diverse variety of subjects pertaining to women and older generations. This research paper aims to understand the current trends of the OTT space in India and evaluate its possible impact on various consumer segments.

To understand the current consumption patterns and its impact, it is imperative to understand the intrinsic relationship between mass media and its impact on the social fabric of the society. Television, cinema and advertising have always had an impact on the society and vice- a-versa. From drama, to politics, to sports, to changing gender roles, to revolutionary thoughts, to realistic issue based themes, to parallel cinema becoming more 
mainstream, content has changed over time to suit contemporary sensibilities. From strictly regulated TV and Films censorship, to the current times of free to all internet enabled OTT content, the new age mediums have empowered the consumer to make his/ her own choices.

As per the BCG report, there is scope for coexistance of numerous OTT models in India and world over. These models include - SVOD (subscription-based platforms), AVOD (advertising-based platforms) and TVOD (transaction-based platforms). But, before we get there, let us have a look at the history of media and entertainment market in India succinctly.

\section{Historical context}

India has been a land of exploration and expression through various forms of art. From singing, to dancing, to painting and other forms of handicrafts have always had a special place in our society. Owing to its rich heritage, Hindustan has been a cultural melting pot of numerous art forms which have filled our hearts with warm and amazed the world with its diversity. As times progressed and eras evolved from Indus Valley Civilisation, to Harappan Civilisation, to Mauryan Empire, Gupta Era, to the time of political instability, Mughal Empire, British Raj and the Modern day Indian Republic, our culture got influenced by a diverse range of art forms from around the world. And, our richness and interest in entertainment and its expression in various forms only grew and become finer in nature.

When the British were ruling India, tools of mass communication were used as a medium to spread awareness - share ideas, enthuse masses towards revolution, talk about our rights and keep the fire of Indian freedom struggle ignited. Entertainment was luxury reserved for the niche group of fortunate few in power - mostly, the royalty. Primary source of entertainment would be live dance performances, live sporting events (indoor and outdoor), presentation of fine arts in form of paintings and more. But, as eras evolved and our economic conditions improved, media and entertainment shaped up as flourishing industry including a diverse range genres like News, Entertainment, Sports and more. India's media and entertainment industry consists of numerous parts, such as television, print and films, under its folds. Smaller segments, such as radio, music, out-of-home advertisement, animation, gaming and visual effects (VFX) and internet advertisements are also included. But, for the context of this research, we would be talking about the current Indian Republic period post 1947 and to keep the conversation more contemporary and centred around uptake of TV, we would like to discuss nuances from a post-liberalisation perspective.

\section{A brief history of TV in India}

Television once used to be a scare luxury which could be afforded by a niche few in India. One or two channels available in black and while colours were enough to catch attention and ignite imagination of the ignorant and economically compromised Indian audience. As decades passed by, technology grew and so did the creative canvas for thematic exploration. From just being a medium of information dissemination to becoming a $24 \times 7$ companion, the role of television screen has evolved dynamically in the past 50 years.

Table 1: Evolution of TV in India

\begin{tabular}{|l|l|}
\hline Timeline & $\begin{array}{l}\text { Progression with regards to TV } \\
\text { reach and programming }\end{array}$ \\
\hline 1950s & $\begin{array}{l}\text { A television was put up for } \\
\text { demonstration at an exhibition by } \\
\text { B. B. in the Teynampet town of } \\
\text { Madras (now Chennai). } \\
\text { Terrestrial television in India } \\
\text { began on 15 September 1959 with } \\
\text { an experimental telecast in Delhi } \\
\text { with a small transmitter and a } \\
\text { makeshift studio. }\end{array}$ \\
\hline 1960 s & $\begin{array}{l}\text { As a part of All India Radio } \\
\text { (AIR), regular transmission } \\
\text { started in 1965. }\end{array}$ \\
\hline 1970 s & $\begin{array}{l}\text { The television service was } \\
\text { subsequently expanded in 1972 to } \\
\text { Bombay and Amritsar. Just seven } \\
\text { Indian cities had television } \\
\text { services up until 1975.A } \\
\text { significant move taken by India } \\
\text { to use television for growth has } \\
\text { been the Satellite Instructional } \\
\text { Television Experiment (SITE). } \\
\text { The programmes were mainly } \\
\text { created by Doordarshan (DD), a } \\
\text { member of the AIR at that time. }\end{array}$ \\
\hline
\end{tabular}




\begin{tabular}{|c|c|}
\hline 1980s & $\begin{array}{l}\text { With shows such as Hum Log } \\
\text { (1984-1985), Wagle Ki Duniya } \\
\text { (1988), Buniyaad (1986-1987) and } \\
\text { comedy shows such as Yeh Jo Hai } \\
\text { Zindagi (1984), other than the } \\
\text { popular mythological dramas } \\
\text { such as Ramayan (1987-1988) and } \\
\text { Mahabharat (1989-1990) glued } \\
\text { millions to Doordarshan and later } \\
\text { to Chandrakanta (1994-1996), the } \\
\text { 1980s was the era of DD. }\end{array}$ \\
\hline 1990s & 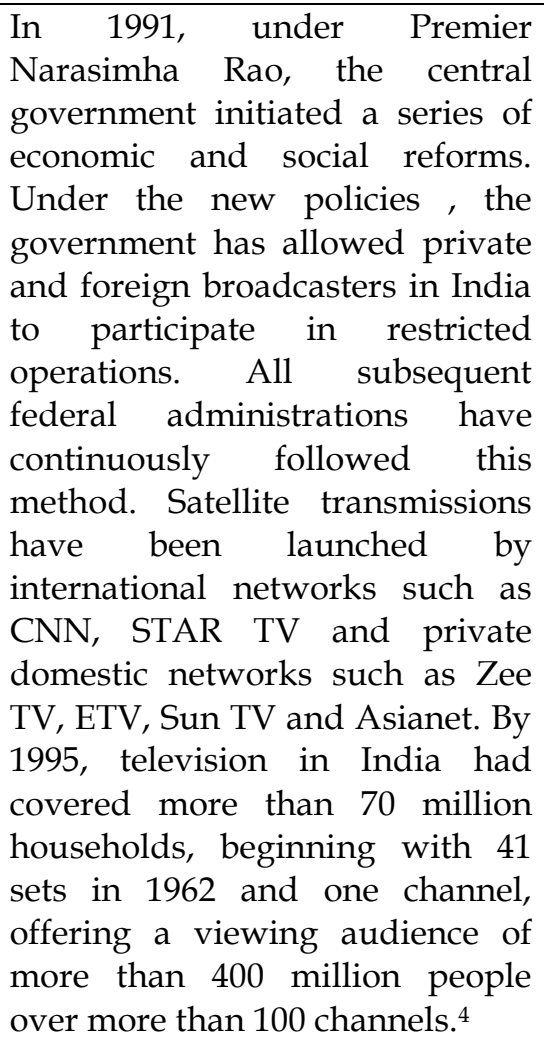 \\
\hline $2000 \mathrm{~s}$ & $\begin{array}{l}\text { The nation had over } 857 \text { channels } \\
\text { as of 2016, of which } 184 \text { were pay } \\
\text { channels }\end{array}$ \\
\hline
\end{tabular}

(Source: Self)

\section{Adoption of OTT in India}

While OTT has become the new buzzword, it might be hard for some to believe that OTTs in India are over a decade old platform. Reliance Entertainment launched the first OTT platforrm in india in the year 2008. ${ }^{5}$ Thereafter, India received its first OTT mobile app called nextGTv, which provided access to both normal TV and on-demand content including live-streaming of one of the most popular sporting event - Indian Premier League matched in the year 2013-14. The medium gained popularity when biggies like Zee and Sony entered the market with DittoTV (Zee) and Sony Liv. DittoTV went on to aggregate content from channels including Star, Sony, Viacom, Zee and more and this led to a wider adoption of the platform per say.

Today, India enjoys services from over 40 OTT providers including domestic and international players like Netflix, Amazon Prime, Disney+ Hotstar, Zee5 and Eros Now. According to a credible research firm - Price Waterhouse Coopers Global Entertainment and Media Outlook 2019-23, the over the top (OTT) market in pegged to growth at the rate of 21.8 \% CAGR, from Rs. 4,464 crores in 2018 to Rs. 11,976 crores in 2023. Meanwhile, FICCIEY Report 2019 suggests the market will reach Rs 24 billion by $2021 .^{6}$

To consume content via OTT medium, it is imperative for the consumer to have access to an internet enabled device like a Smart TV, Mobile phone, Laptop or a Tablet. Owing to the basic need for technology access, younger generation is much more comfortable interacting with OTT platforms but post COVID the read and adoption has increased manifolds. The BCG report 'Entertainment Goes Online'7 - suggests that OTT consumers can be classified under three main categories:

- Traditionalists - who primarily consume on other than OTT platforms

- OTT Experimenter - who have significant consumption on both conventional and OTT platforms

- Early Adopter - whose primary consumption occurs on OTT platforms. While early adopters are still a more urban phenomenon, going forward it will be more equally distributed.

According to the 2017 Ficci-EY media and entertainment industry survey, rural users, who are projected to rise from 38 percent to 52 percent, would drive growth in India's Internet user base by 2021. ${ }^{8}$ This is bound to have a huge effect on the content form and language that will need to be created. Regional content often reaches out to the Indian diaspora abroad, not just within the country. To put this in context, it is imperative to understand the Indian vernacular landscape inclusive of all mediums of maximum media 
and mediums. See Table I - Indian vernacular media landscape

Table II: Indian vernacular media landscape

\begin{tabular}{|l|l|}
\hline 124 & $\begin{array}{l}\text { Newspapers published in 22 regional } \\
\text { languages }\end{array}$ \\
\hline 23 & $\begin{array}{l}\text { AIR originated programming 23 } \\
\text { languages and 179 dialects }\end{array}$ \\
\hline 226 & $\begin{array}{l}\text { Entertainment, news and movie } \\
\text { channels in 13 regional languages }\end{array}$ \\
\hline $45 \%$ & $\begin{array}{l}\text { People recognise Hindi as their } \\
\text { mother tongue }\end{array}$ \\
\hline 5308 & $\begin{array}{l}\text { Use other regional languages as their } \\
\text { native language }\end{array}$ \\
\hline $10-$ & $\begin{array}{l}\text { Is the English speaking population, } \\
\text { but only 8\% consume OTT content in } \\
\text { native language }\end{array}$ \\
\hline
\end{tabular}

(Source: Inc42 report 'India's OTT Market

Landscape Report 2020')

Streaming networks have recognised the potential of regional languages that are spread worldwide by their speakers. For example, Maya Thirrai's Tamil show by ALTBalaji witnessed viewership in the Middle East, the United States, and the United Kingdom, which house huge sections of the Tamil population. ${ }^{9}$

\section{Impact of COVID on TV viewership, including OTT}

If 80 s was an era of DoorDarshan and 90s dominated by private broadcasters, media and entertainment gurus predicted that 2000s will be an era dominated by technology enabled entertainment beyond TV screens - there will be greater uptake for 'content of demand' and by that we don't just mean the genre and nature of content but the choice of time, place and device as well.

OTTs are not limited to audio visual content, the audio only market makes for a significant share of this market. While platforms like StoryTel and Audible are gaining popularity, innovative offerings like Graphy (by homegrown edtech soonicorn Unacademy) are still to be categorised as OTTs. Needless to say, this space is buzzing for numerous innovative solutions and offerings consistently. Players are leaving no stone unturned to catch attention of the consumer, grow their user base and retain each user for a longer duration than before. ${ }^{10}$
Reports suggest that Bollywood and Cricket rule the hearts of Indian consumers on OTT platforms and release of big banner movies like Amitabh Bachhan starrer Gulabo Sitabo, Vidhya Balan starrer Shakuntala Devi, Late Sushant Singh Rajput starrer, Dil Bechara on platforms like Amazon Prime and Disney + Hotstar have triggered a new trend in B town. While this necessity was actually the mother of this innovation, market analysts who watch the cinema space worry that if this trend impacts consumer behaviour, it might be a challenge to get them back to cinema halls and this might have a long term impact on sustainability of the medium in the country, especially the urban markets.

In context of these nuances, it is seen that uptake for OTT has gone up considerably owing to COVID lockdown in India and Globally. This change in consumer behaviour is interesting to observe and evaluate as there are numerous layers in this consumption pattern which need to be unravelled and understood from various angles and point of views. Aspects like nature of content being consumed, timings for different genres of consumption, consumer age and commensurate content consumption, TV channels v/s OTT providers, impact of the medium on advertising patterns, innovative deals and discount packaging and much more. Therefore, this study aims to specifically review consumer consumption trends of the past six months and look at certain milestones and highlights which become the poster boy of OTT adoption / success.

\section{REVIEW OF LITERATURE}

Understanding the revolution called OTT TV Growing internet penetration and access and availability of multiple screens and gadgets have encouraged the development and growth of OTT platforms in the past decade. While there are multiple forms of OTT platforms, OTT TV refer to high quality video content streamed directly from the provider, on to a user's screen (mobile, tablet, laptop, TV etc.) via Internet Protocol over a public network. What is critical to understand here is the fact that OTT democratises content accessibility and empowers the consumer manifolds as it bypasses cable, broadcast, and satellite television platforms, the companies that traditionally act as a controller or distributor of such content. Majority literature available 
regarding advent and adoption of OTTs hint towards this key differentiation of the platform and medium which emphasis on its B2C approach.

There are various kinds of OTT services including OTT messaging, OTT voice calling, video calling and OTT TV. OTT TV is becoming increasingly popular because of the ease and convenience it offers. It is mostly called digital television or internet driven TV platform or even as streaming television. As compared to diffusing a television signal from a terrestrial broadcast or satellite, this signal is received via Internet or from a mobile phone network. The access to content in this case is monitored and governed by the content distributor, connected to a computer, Laptop or smart television set through either an app or a separate OTT dongle or box.

USA's largest and globally most popular and penetrated streaming service Netflix entered India in the year January 2016. By mid of the next year in 2017, the provider was registered as a limited liability partnership (LLP) and started commissioning content from domestic production houses. It earned a net profit of ₹2020,000 (₹2.02 million) in the year 2017. In fiscal year 2018, Netflix earned revenues of ₹580 million. ${ }^{11}$ According to Morgan Stanley Research, Netflix had the highest average watch time of more than 120 minutes but viewer counts of around 20 million in July 2018.12 As of 2018, Netflix has six million subscribers, of which $5-6 \%$ are paid members. ${ }^{13}$ Hotstar invested INR 120 crore in the production of original content such as "Hotstar Specials" in 2019. On Hotstar, 80\% of the audience comes from drama, films and sports programmes. $96 \%$ of viewing time on Hotstar comes from videos longer than 20 minutes, according to Hotstar 's India Watch Report 2018, while one-third of Hotstar subscribers watch TV shows. Although customers profit from the complementary services provided by companies, competition between providers of OTT services is forcing companies to look for international markets.

India is a land of diversity and same clearly reflects in its dynamic OTT market space which includes - 40+ active video OTT players, $15+$ active music streaming OTT players, $40+$ active podcast players and beyond. Over $30 \%$ prefer to consumer content in regional language and the most preferred languages include - Tamil, Telugu, Marathi, Bengali and Hindi. Bundled content is the most preferred consumer choice but subscription is the most adopted business model by OTT players. Short form, originals and web series content categories are gaining immense consumer attention. ${ }^{14}$

\section{Existingliterature on the OTT space}

The literature on the topic remains somewhat limited and skewed, despite the drastic changes that OTT services have introduced to the media and entertainment industry. In terms of several threads, common research themes so far can be summarised. First, several case studies illustrate the development of OTT services. Second, it is popular to address the viral effect of OTT services on the conventional media industry. The competitive dynamics between OTT and conventional pay TV platforms was hypothesised through niche research. The results shed light on the effect of established systems by explaining how OTT systems overlap or are competitively superior to existing services ${ }^{15-16}$ Built a TechnologyPolicy-Consumer (TPC) model and examined how the introduction of OTT services has impacted the technology / industry, public policy, and consumer / culture aspects of the US media industries. Analyses of OTT services that revolutionise conventional stages of development, delivery and consumption often offer an important viewpoint on understanding the latest features and future developments in the media industry caused by OTT services. ${ }^{17}$

Third, user motivations for adopting OTT services have been investigated by a number of scholars ${ }^{18}$ Comparing TV consumption motivations, Yi-Ning Katherine Chen (2016) ${ }^{19}$ examine how OTT services can serve as a substitute for TV in Taiwan. Finally, as different businesses continue to broaden their offerings to the online video streaming market, net neutrality laws or recommendations about how to regulate the emerging industry are discussed. Therefore, what is evident from literature available domestically and internationally is the fact the OTT has revolutionised the way audience consumer content and this has impacted not only the media and entertainment industry but the entire eco-system, including content, creativity, formats, regulations, telecommunications, device market including 
software and hardware and last but not the least, one of the most crucial peg of the puzzle, the internet providers.

\section{Factors influencing adoption of OTT TV}

Researchers have reviewed consumer behaviour in certain studies and reviewed theories to understand and predict consumer behaviour with regards to OTT adoption. Growing technology adoption and internet penetration have been cited as clear benefits for OTT growth in past decade internationally. Numerous authors have used various models including - Technology Acceptance Model (TAM), (Davis, 1989), Theory of Panned Behaviour (TPB) (Ajzen, 1991), Diffusion of Innovation (DOI), (Roger, 1995), Theory of Reasoned Action (TRA) to review and understand the acceptance of a new technology by customers and correlate it with adoption of OTT media including TV, voice, interactive and others. ${ }^{20}$ With respect to OTT platform, TAM is used mainly by various authors like Cha, 2013; Cha and ChanOlmsted, 2012. In which two major variables i.e. perceived ease of use and perceived usefulness have been identified as crucial factors which predicts users' adoption of new technology. ${ }^{21}$

Based on these key theories ${ }^{22}$ of technology adoption and acceptance, a research was done - to study the impact of key elements including - Apparent Ease of Use, Apparent Usefulness, Apparent Enjoyment, Role of Customisation, Compatibility, Content Quality and User Interface on OTT adoption (See Fig I - Factors impacting acceptance of new technology). It was found that four variables were determined, i.e. Customization, user experience, perceived pleasure and quality of content have had an important and positive effect on users' attitudes toward OTT media adoption. Content quality has been shown to have the greatest effect on developing a positive attitude towards embracing the OTT media platform. This implies that a very important aspect is the quality of content delivered on the OTT media site. Also, from the previous researches, it has been found that people switch from Traditional media to OTT media due to the good content quality provided in OTT media.
Fig I: Factors impacting acceptance of new technology ${ }^{23}$

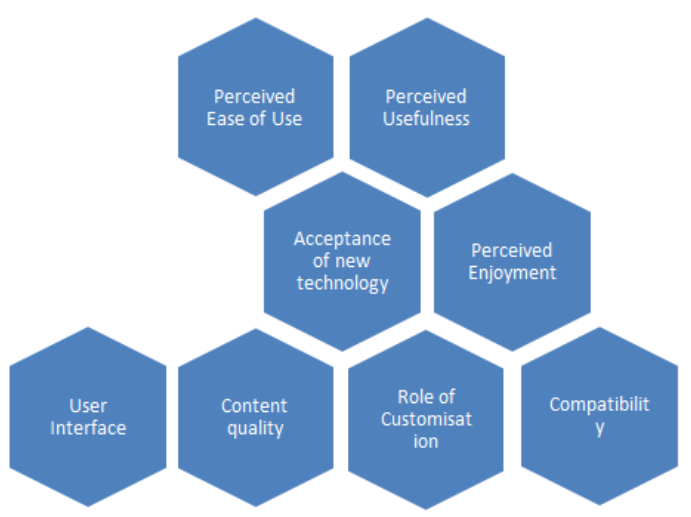

Prevalent business models and consumer preferences

As per an industry report by BCG and CII called 'The Trillion (and growing) touchpoint story recognising the monetisation conundrum', released in November 2019, consumption of daily digital video data grew from 11minutes to 24minutes in the last two years. With internet data plans going as low as INR 99 per month / INR 49 per month for regional players and smartphones becoming cheaper, there is no stopping the OTT players from gaining more traction. But, this growth brings competition and the fight between local and international players only intensifies. From content creation, to production, to creating local content libraries and exploring regional markets is just like scratching the surface of this vast and deeply diverse Indian market. But, that is the only route to opening the doors of monetisation for this extremely price sensitive Indian market. At the same time, the traditional digital players are facing an extremely tough competition combating emergence of telcos backed players such as Reliance, Airtel as well as traditional DTH players like Tata Sky and Dish TV.

As per the Inc42's latest report 'India's OTT Market Landscape Report 2020'24 - There are 3 key concerns faced by the service providers / OTT platform owners -

Challenge 1 (Paywall Vs Free Customers) The digitally sophisticated user base that prefers content behind the paywall has a total size of just 18 million in 2018, according to the Zee5 whitepaper. Compared to the over 310 million conventional digital consumers (in 2018) consuming video content online either free of 
charge or bundled with telcos and other distribution channels, this is very poor. (See Table II - Indian OTT Video Streaming Players)

Table III: Indian OTT Video Streaming Players (Types of consumer breakdown)

\begin{tabular}{|c|c|c|c|}
\hline $\begin{array}{l}\text { Consumer } \\
\text { Type }\end{array}$ & $\begin{array}{l}\text { Approx } \\
\text { User } \\
\text { Base in } \\
\text { Min } \\
(2018)\end{array}$ & $\begin{array}{l}\text { Content } \\
\text { preferences }\end{array}$ & $\begin{array}{l}\text { Mode of } \\
\text { Consumption }\end{array}$ \\
\hline $\begin{array}{l}\text { Digital } \\
\text { Sophisticates }\end{array}$ & 10 & $\begin{array}{l}\text { International } \\
\text { original } \\
\text { shows } \\
\text { movies, } \\
\text { typically } \\
\text { behind } \\
\text { paywall a }\end{array}$ & $\begin{array}{l}\text { Tablet I Smart } \\
\text { TVs I } \\
\text { Smartphones }\end{array}$ \\
\hline $\begin{array}{l}\text { Digital } \\
\text { Enthusiasts }\end{array}$ & 190 & $\begin{array}{l}\text { International } \\
\text { original } \\
\text { shows \& } \\
\text { movies, } \\
\text { freemium } \\
\text { content } \\
\text { preferred }\end{array}$ & $\begin{array}{l}\text { Tablet I Smart } \\
\text { TVs I } \\
\text { Smartphones }\end{array}$ \\
\hline $\begin{array}{l}\text { Digital } \\
\text { mainstream }\end{array}$ & 310 & $\begin{array}{l}\text { Free content } \\
\text { or content } \\
\text { bundled with } \\
\text { mobile and } \\
\text { DTH } \\
\text { subscription }\end{array}$ & Smartphones \\
\hline Fringe user & 10 & $\begin{array}{l}\text { Mobile } \\
\text { messaging } \\
\text { and free } \\
\text { bundled } \\
\text { content }\end{array}$ & $\begin{array}{l}\text { Feature } \\
\text { Phones I } \\
\text { Entry-level } \\
\text { Smartphones }\end{array}$ \\
\hline
\end{tabular}

(Source: Zee5 Whitepaper)

Challenge II (Subscription Vs Free Vs Freemium Models) Most players are experimenting with subscription-based video on demand (SVOD) business models, in one way or the other, despite the number of paid subscribers being substantially smaller than free content users. Only TVF and MX Players have advertisement-based on-demand video (AVOD) business model content. Examples of a few players offering content based on different models:

- AVOD - TVF, Arre and MXPlayer

- SVOD - Amazon, Netflix, Apple TV, BigFlix, Youtube et.

- Freemium - Eros, Hotstar, Sony Liv, Zee5, YuppTV

Challenge III (Monetisation Vs Bundled content) - For both the international and local
Indian platforms, this is one major challenge. As opposed to bundled plans provided by telcos and DTH players, individual subscription packs are extremely highly priced and do not suit the pocket of an average Indian customer. For most players, this approach does not seem to work well, as they have to rework their plans to make them more palpable for the Indian palate and wallet. Initially, Netflix arrived with an INR 700 a month subscription plan, but was forced to reassess its strategy. Similarly, though still promoting independent outlets, Telcos monetizes its own online video streaming outlets. Same is true for DTH players like Tata Sky.

\section{OBJECTIVES OF THE STUDY}

The available literature suggests that OTTs have had a deep impact on the media, entertainment, telecom and the IT sector. While multiple factors have contributed to its growth so far, players have still scratched the surface when it comes to exploring the potential of the Indian market. The COVID-19 pandemic occurrence gave an impetus to the adoption of OTT in India at a national scale including urban and regional markets alike. Similarly, the big fight between existing players in leading to revamp of regulations, marketing formats and advertising on the platform. Keeping all these factors in mind, this study aims to explore the following aspects:

- To study the key trends around OTT adoption trigged by COVID-19 in urban India within Delhi-NCR

- To study and evaluate comparative audience preferences and trends around OTT v/s TV viewing

- To assimilate and study the consumer opinion regarding 'likes and dislikes of OTT as a platform'

\section{RESEARCH DESIGN AND METHODOLY}

In order to answer the above research questions, a mix of quantitative and qualitative research analysis was adopted. The researchers carried out a detailed primary research to study consumer preferences and trends regarding OTT adoption and this was supported by secondary research. As part of secondary research, the researchers reviewed reports from different organisations, studied past global literature regarding OTT adoption and trends, referred white papers, newspaper 
extracts and numerous other research reports.Qualitative and quantitative primary research was done to understand the thoughts and opinions of consumers regarding OTT adoption and content consumption during COVID-19. The lockdown forced people to stay indoors and restricted social mobility further reduced the sources of recreation and entertainment. Therefore, it was imperative to understand if people turned to OTT platforms led content to keep themselves engaged or were there other reasons which were contributing to the growth and adoption. These nuances could only be understood by way of qualitative research focusing on understanding the reasons for actions. The aim of this primary survey was to understand consumption patterns and key trends to analyse how they correlate with secondary information available via journals, research reports and news stories. Appended below are section wise insights and figures along with interpretations.

Method used:

Survey method was used to carry out the primary research. As this research was conducted in September 2020 during the scare and caution of COVID-19, social mobility was restricted and digital survey method was used to carry out a detailed consumer study.

\section{Sampling:}

As this was a broad-based study, the age group of 18 to 60 was considered for the purpose of research and a random sampling approach was adopted. A sample of 80 respondents completed the entire survey within a timeframe of two weeks and this sample was evaluated for the purpose of the study.

Tool used for data collection:

A structured questionnaire carrying 14 close ended questions and one open ended question was administered via google form. The questionnaire had relevant queries to evaluate respondent insights around key areas including - OTT uptake, rationale and reasoning, timelines, factors of dissonance etc.

\section{DATA INTERPRETATION AND ANALYSIS}

Basis the primary consumer survey conducted across Delhi NCR, the researchers have tried to understand the nuanced trends across OTT viewership. From content preference, to timelines, to growth evaluation, to understanding pros and cons - an in-depth analysis has been done for the purpose of the study and the data has been evaluated first hand for a deeper understanding of these trends. As the lockdown occurred in March 2020 and this data was collected in September 2020, the insights are fairly neutral and balanced.

A. Age and Gender representation: This is a section carrying basic background information on the age and gender of the respondents.

Age group of respondents -Largely dominated by younger audience in the age group of 18 years to 35 years

- $49.2 \%$ respondents were in the age group of 18 years to 25 years

- Followed by $31.1 \%$ in the age group 25-35 years

- $11 \%$ in the age group 35-45years

- $8 \%$ in the age group of 45 years and beyond

Gender: There was a balanced representation of gender in the research, with $51 \%$ female and $49 \%$ male respondents

Inference: While there was a balanced representation of gender in the survey, the majority respondents were from an age group of 18 years up to 35 years.

B. Impact of COVID lockdown on AV content consumption: This section elaborates key trends around the level of change in content consumption habits during COVID lockdown, including impact on screen hours, timeline of consumption and reason for change beyond having some extra time at hand in the day.

Impact of COVID on screen time:Owing to the lockdown and restrictions on social mobility, people had to stay at home and operate from restricted premises. Therefore, mode of entertainment and news consumption also became limited as people even avoided sourcing a physical newspaper from local vendors and switched to audio visual modes on news consumption. In the survey, the researchers found that over $87.3 \%$ respondents felt their screen time has gone up individually 
and as a family post COVID, while $9.5 \%$ did not observe a significant change. Close to 3.2\% respondents were unable to make any notable observation in this regard and therefore could not say if their screen time increased or not.

\section{Chart 1: Impact of COVID-19 on screen time}

Screentime gone up during / Post COVID personally and as a family

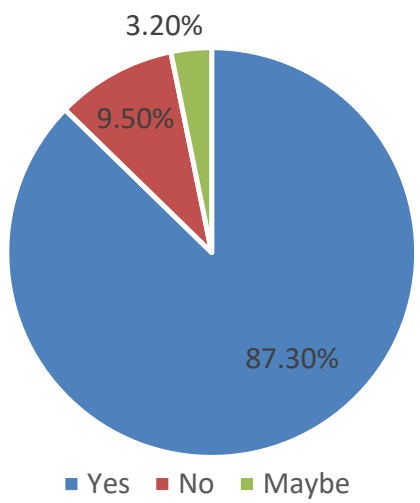

(Source: Primary survey)

\section{Reason for increased screen time:}

- Growing content availability on OTT platforms $-32.1 \%$

- Lack of entertainment options - $28.3 \%$

- WFH give me the flexibility and choice- $26.4 \%$

- Became more tech savvy during COVID lockdown - 13.2\%

- To keep my kids engaged - NA

- To keep my parents/elders engaged-NA

\section{Chart II: Rational for increased screen time}

Reasons for increased screen time

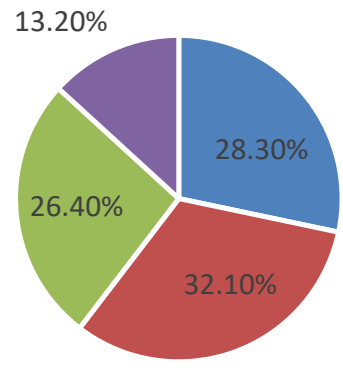

- Lack of entertainment options

- Growing content availbility on OTT platforms

- WFH gives me the flexibility and choice

- Became more tech savvy during COVID lockdown

(Source: Primary survey)

Inference: There was a notable increase in the screen time of the respondents during the COVID lockdown period. Majority respondents held growing entertainment choice via OTT content responsible for their increasing screen hours, but keeping kids or elderly persons in the family engaged was not the reason for growing screen time of the family. People choose to restrict social mobility and turned to e-commerce and home delivery mediums for all their day to day needs, they had more time at hand. Therefore, their need for entertainment went up but restricted outdoor activities like sports, recreational engagements, movies or theatre etc. more and more respondents resorted to digital content consumption via screens - TV, Tablets, Laptops and Smartphones. Additionally, it is a part of human psychology - when physical mobility is restricted, our creative side takes over and resort to imagination which helps us travel mentally to places.

Estimated screen time through the day:

- 2 to 4 hours $-38.7 \%$

- 4 to 6 hours $-24.2 \%$

- 1 to 2 hours $-19.4 \%$

- 6 hours and beyond $-17.7 \%$

\section{Chart III: Estimated daily screen time}

Estimated screen time (entertainment led) on a daily basis

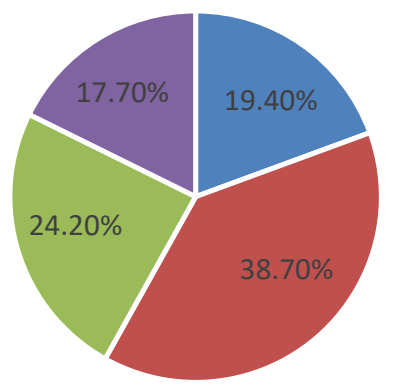

$$
\begin{array}{ll}
\text { - } 1 \text { to } 2 \text { hours } & -2 \text { to } 4 \text { hours } \\
\text { - } 4 \text { to } 6 \text { hours } & -6 \text { hours and beyond }
\end{array}
$$

(Source: Primary survey)

Inference: In line with numerous researches and insights from this survey, it is being seen that adults are spending anywhere between 4 to 7 hours or more consuming content for entertainment and recreational purposes online. Same is reflected in the survey research where over $80 \%$ admit to consuming content for 2 hours or more, on an average every day. 
Dominant time of the day when content is consumed:

- Afternoon - meal time with family - NA

- Evening - de-stressing post work $-9.5 \%$

- Late night - meal time / family time - $25.4 \%$

- Randomly anytime basis schedule - after everyone is asleep / binge watching - $65.10 \%$

\section{Chart IV: Timelines for content consumption}

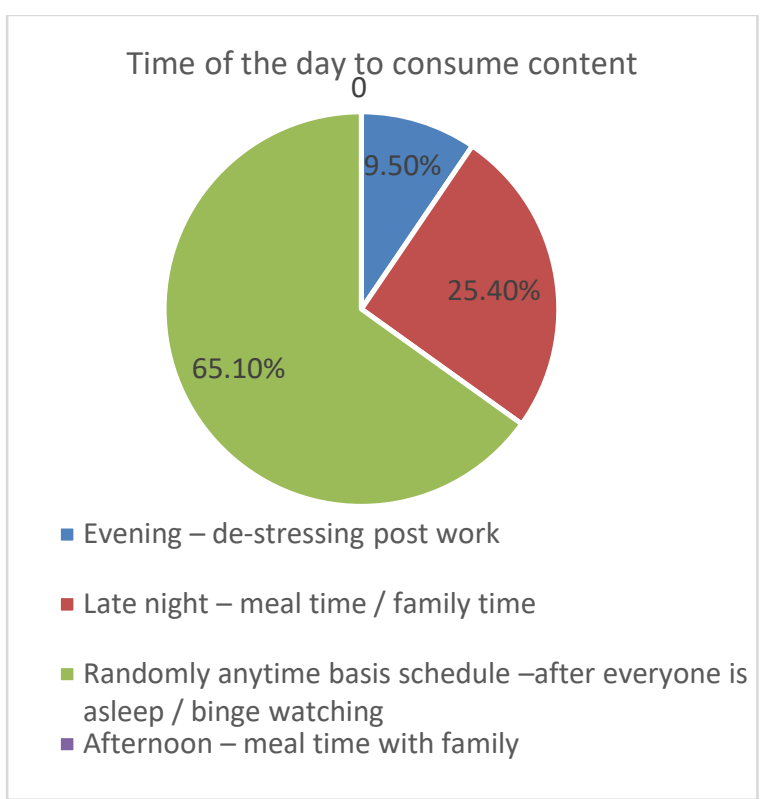

(Source: Primary survey)

Inference: While some may believe that the time of consuming content is not reflective of any trend, it is increasingly being reported that availability and flexibility of content is increasingly leading to addiction. The survey throws an interesting insight that owing to the lack of routine that WFH or digital schools is fuelling, more and more respondents are consuming content at random hours through the day. Not only is it throwing discipline out of the window, the leaning towards the evenings or late nights is triggering inactivity after a hectic day or work, making content consumption the only choice of recreation.

C. Television $\mathrm{v} / \mathrm{s}$ OTT - the tug of war: While there is consistent pick-up of OTTs and an exponentially growing user base, it is imperative to look at this trend in context of the TV audience and evaluate how this correlates with TV or impact the user base of the medium.

\section{Preference of content - TV v/s OTT content:}

- OTT over TV - 75\%

- $\quad$ TV and OTT alike $-21.7 \%$

- TV over OTT - 3.3\%
Chart IV: Preference between OTT v/s TV

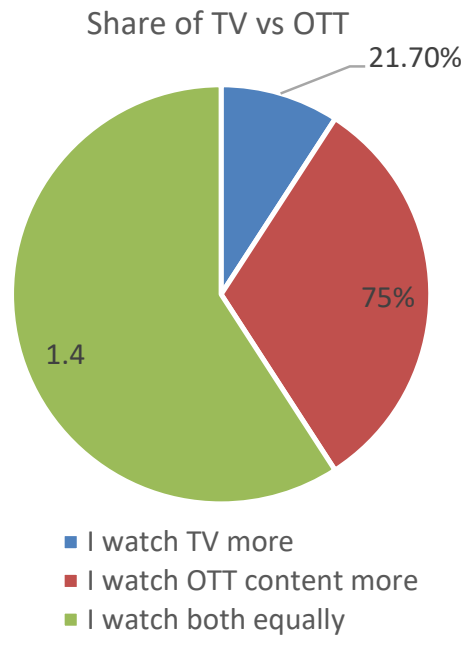

(Source: Primary survey)

Inference: It is clear that OTT exposure and adoption is growing and as this survey is specific to the metro cities, love and liking for OTT is significantly higher that Television. While there is a notable number of people who like watching both platforms alike, the purpose and nature of content consumption may differ.

\section{Rationale for OTT preference}

- Content of choice - $54.1 \%$

- Time of choice - $41 \%$

- Gadget of choice - $4.9 \%$

- Language of choice - NA

\section{Chart V: Rationale for platform preference}

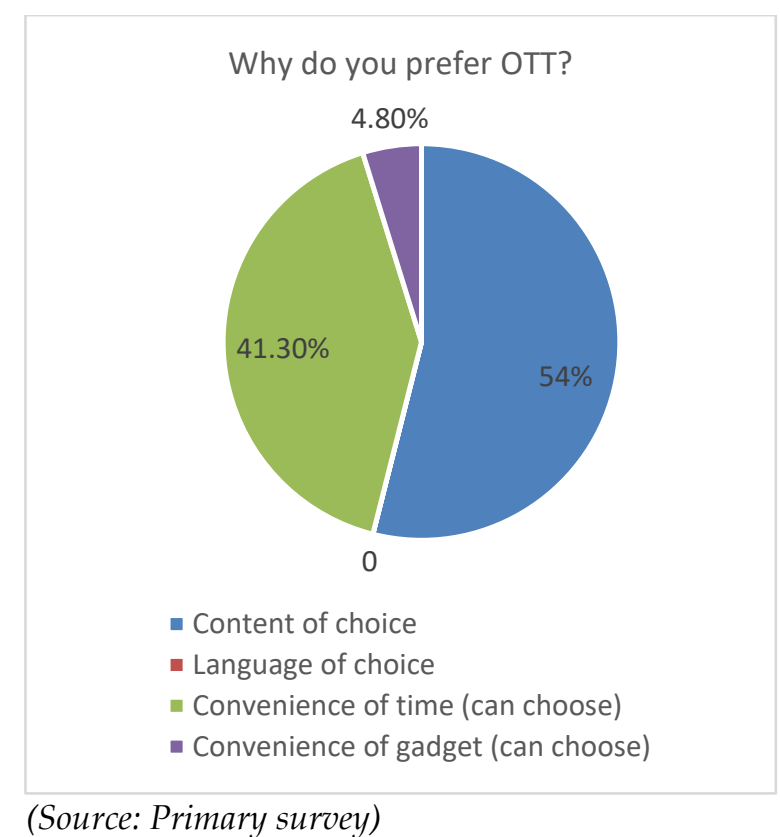


Inference: OTT platforms are primarily loved for the immense flexibility and convenience they offer to the audience. From choice of content, to timing, to the fluidity of logging in from any device, all contribute to the growing user base of the medium and platforms. While content remains the king with 54\% respondents citing 'choice of content' as the key reason for choosing OTTs, flexibility of watching anytime on any device comes in close second and third reason for people to opt for the OTT platform.

D. The OTT war - pros and cons: Access to OTT platform comes at an additional cost which is over and above the tradition audio-visual medium of television. Additionally, it also requires a high speed internet connection and availability of a suitable gadget, which makes access to the experience relatively more demanding.

\section{TopFour OTT platforms}

- Netflix - 62.7\%

- YouTube $-18.6 \%$

- Amazon Prime - $10.2 \%$

- Hotstar $-6.8 \%$

\section{Does paying extra for OTTs bother you:}

- Yes $-54.1 \%$

- No- $27.9 \%$

- Maybe - $18 \%$

\section{OTT Likes and dislikes:}

- Likes: diversity of content, portability, trendy, Ad free, User friendly

- Dislikes: High subscription charges, distractions (content overload), need for high speed internet, can be addictive, no censorship

Inference: While pros and cons, or likes and dislikes of OTT platforms is a very broad subject and demands detailed study in itself, it is a fact that diversity of content and formats has opened up a new field of entertainment for the Indian audiences. While enough has been said about the likes and the exponential growth is a clear indicator of the same, there is a downside to OTTs which is also talked about evidently. There is a very interesting dichotomy highlighted by respondents in the research - on one hand they highlight advertisement free entertainment as a key like, distractions in form of content overload is a clear downside. This might be an interesting trend for marketers to study in the near future. Also, lack of censorship and complete viewer discretion is another aspect up societal evaluation as it has very deep psychological impact on impressionable young audience.

\section{KEY FINDINGS:}

1. Over $87 \%$ respondents felt their screen time went up post COVID, while $9.5 \%$ did not observe a significant change

2. Growing content availbility on OTTs $(32.1 \%)$ and lack of any other entertainment sources $(28.3 \%)$ were the primary reasons for increased OTT screen time

3. For over $26 \%$ respondents, flexibility of working from home was an added advantage to login to OTT platforms anytime of the day

4. Surprisingly as against the common notion, engaging kids or elderlies in the family was not the stated reason for increased screen time

5. While $38.7 \%$ people observed a screen time of 2 to 4 hours daily. A vast majority of $40 \%$ plus respondents agreed to watch a screen for over 4 hours in a day.

6. Unfortunately, over $65 \%$ respondents do not follow any discipline of timelines in terms of screen time and mostly indulge in binge watching

7. While OTT is clearly ahead of TV in terms of platform preference with $75 \%$ people liking it over TV, there are still $20 \%$ plus respondents who like both TV and OTT alike

8. Content of choice $(54.1 \%)$ and convenience of time (41\%) are the two main reasons for OTT preference, with gadgets of choice $(4.9 \%)$ as the third reason

9. Netflix (62.7\%), YouTube (18.6\%), Amazon prime $(10.2 \%)$ and Hotstar $(6.8 \%)$ are the top 4 platforms of choice in that order

10. In terms of costs, over $54 \%$ respondents are concerned over the additional OTT cost, while $27.9 \%$ respondents do not mind it.

11. Last but not the least, despite the growing consumption of OTTs - High subscription charges, distractions (content overload), need for high speed internet, addictive nature, no censorship are stated concerns of respondents.

12. Yet, diversity of content, portability, trendy, Ad free content and platform User friendliness are immensely loved 


\section{CONCLUSION}

Viewing content on any medium is a matter of behaviour which converts into a habit over a period of time. Indians for long have yearned for diversity of content. A common family television enabled with limited channels restricted the imagination of young India. This imagination was tapped and explored by OTT players optimally during COVID 19 and the flexibility of accessing a range of content on personal devices including smartphones and tablets gave young India the freedom to watch what they desired.

Yet, OTT players have just been able to touch the tip of the ice berg, there is immense potential to dive deeper into the regional Indian market in times to come. With just 40 OTT platforms and limited regional content, this medium has created a new niche for itself in urban India. COVID 19 has played a very significant role in mass adoption of the medium in urban regions where people have better paying power than semi-urban or rural India.

OTTs are being perceived as aspirational medium of content consumption and with all the noise in right circles, they are fast converting the fence sitters across age groups and demographic regional. COVID 19 brought with itself some factors which became the new normal, like working from home, which have seemed to offer flexibility of schedules to many. A random walk and tea time with a colleague have been replaced with a $20-30 \mathrm{~min}$ quick episode of one's favourite series available on an OTT platform. All researches point to the growing duration of video content consumption year on year and COVID 19 has proved to be a turned point in furthering this behaviour change.

\section{AREAS OF FURTHER RESEARCH:}

- Study of international best practices and business models to monetising OTT platforms effectively

- Study the psychological impact of OTT on youngsters - "Ban on pornographic sites juxtaposed with availability of uncensored OTT content"

- Study possibilities of innovative and targeted advertising on OTT platforms like narrow casting
- Study the impact of digitisation of media and entertainment on content democratisation

- Study the impact of family staying together during the pandemic leading to the exchange of consumption habits from younger to older generation (reverse parenting)

\section{REFERENCES}

1. ETBrandEquity.com. 2020. Indian OTT Market To Reach \$5 Billion In Size By 2023: Report - ET Brandequity. [online] Available at:

<https:/ / brandequity.economictimes.indi atimes.com/news/media/indian-ottmarket-to-reach-5-billion-in-size-by-2023report/66708675> [Accessed 5 October 2020].

2. Communication, O., 2020. Online Journal Of Space Communication. [online] Spacejournal.ohio.edu. Available at: <https://spacejournal.ohio.edu/issue18/ kunhikrishnan.html> [Accessed 5 October 2020].

3. The Financial Express. 2020. Prasar Bharati Looks At A Turnaround. [online] Available at: <https://www.financialexpress.com/arch ive/ prasar-bharati-looks-at-aturnaround/819379/> [Accessed 5 October 2020].

4. Eresources.nlb.gov.sg. 2020. [online] Available at: <https://eresources.nlb.gov.sg/newspape rs/Digitised/Article/straitstimes19821008 -1.2.221.3> [Accessed 5 October 2020].

5. Dangwal, S., 2020. Reliance Entertainment Launches BIGFLIX, India'S First Global Multi-Language HD Movie Platform. [online] India News, Breaking News, Entertainment News | India.com. Available at: <https://www.india.com/business/relia nce-entertainment-launches-bigflix-indiasfirst-global-multi-language-hd-movieplatform-2074662/> [Accessed 5 October 2020].

6. Alley, W. and Indian\&nbspcustomers, H., 2020. How New OTT Players Can Win Indian Customers. [online] The Financial Express. Available at: <https://www.financialexpress.com/bran 
dwagon/writers-alley/how-new-ottplayers-can-win-indiancustomers / 2020753/\#: :text=According \% 20to\%20PwC's\%20Global\%20Entertainme nt,Rs\%2024\%20billion\%20by\%202021> [Accessed 5 October 2020].

7. The Economic Times. 2020. Indian OTT Market Can Hit \$5 Billion In 5 Years, Says Boston Consulting Group. [online] Available at:

<https://economictimes.indiatimes.com/t ech/internet/indian-ott-market-can-hit-5billion-in-5-years-says-boston-consultinggroup/articleshow/66722045.cms> [Accessed 5 October 2020].

8. Jha, L., 2020. Video Streaming Firms Are Betting Big On Regional Content. [online] mint. Available at: <https://www.livemint.com/Consumer/ renyXrr7uGW5e5bIJ7CDuN/Videostreaming-firms-are-betting-big-onregional-content.html> [Accessed 5 October 2020].

9. Alam, T., 2020. Why OTT Platforms Towards Regional Contents Other Than Hindi. [online] Entrackr. Available at: $<$ https://entrackr.com/2018/06/ottregional-content/> [Accessed 5 October 2020].

10. Mitter, S., 2020. [App Fridays] Unacademy Wants To 'Spark Your Imagination' With Interactive Storytelling App Graphy. [online] YourStory.com. Available at: <https://yourstory.com/2020/08/unacad emy-spark-imagination-interactivestorytelling-app-graphy $>$ [Accessed 5 October 2020].

11. Babar, K. and Laghate, G., 2020. Netflix India: Netflix Leases Space For India Headquater In BKC. [online] The Economic Times. Available at: $<$ https:/ /economictimes.indiatimes.com/t ech/internet/netflix-leases-space-forindia-headquater-in-

bkc/articleshow $/ 67280626 . c m s ?$ from $=\mathrm{mdr}$ $>$ [Accessed 5 October 2020].

12. Staff, e., 2020. Video OTT Revenue In India Expected To Reach Rs 13,800 Crore By FY 2023 - Exchange4media. [online] Indian Advertising Media \& Marketing News exchange4media. Available at: <https://www.exchange4media.com/digi tal-news/video-ott-revenue-in-india- expected-to-reach-rs-13-800-crore-by-fy2023-92262.html> [Accessed 26 October 2020].

13. Android Central. 2020. Netflix Is Getting Crushed By Amazon And Hotstar In India. [online] Available at: <https://www.androidcentral.com/netfli x-getting-crushed-india-and-its-becauseamazon-and-hotstar> [Accessed 26 October 2020].

14. Inc42 Media. 2020. India's OTT Market Landscape Report 2020. [online] Available at: <https://inc42.com/reports/india-ottmarket-landscape-report-2020/> [Accessed 26 October 2020].

15. Daneshyari.com. 2020. [online] Available at:

$<$ https://daneshyari.com/article/preview /466005.pdf> [Accessed 26 October 2020].

16. Han, G. J. J. (2014). Six major shifts and implications of the video distribution ecosystem in the era of N-screen and OTT services: A case of US media industry. Journal of Korea Contents Association, 14(8), 342-364 (In Korean).

17. Banerjee, A., Rappoport, P.N., \& Alleman, J. (2014). Forecasting video cord-cutting: The bypass of traditional pay television. In Demand for Communications ServicesInsights and Perspectives pp. 59-82. Springer US

18. (e.g., Lim \& Lee, 2013 - Lim, S., \& Lee, Y. J. (2013). N screen service users' motivations for use and dissatisfying factors. Journal of Korea Contents Association, 13(3), 99-108 (In Korean).

19. Katherine Chen, Y., 2019. Competitions between OTT TV platforms and traditional television in Taiwan: A Niche analysis. Telecommunications Policy, 43(9), p.101793.

20. Yang, K. and Kang, Y., 2006. Exploring factors influencing Internet users' adoption of Internet television in Taiwan. First Monday,

21. Predictors of television and online video platform use: Acoexistence model of old and new video platforms. Telematics and Informatics, 30, 296-310. AND Cha, J., \& Chan-Olmsted, S. M. (2012). Substitutability between online video 
platforms and television. Journalism \& Mass Communication Quarterly, 89(2), 261-278.

22. Katherine Chen, Y., 2019. Competitions between OTT TV platforms and traditional television in Taiwan: A Niche analysis. Telecommunications Policy, 43(9), p.101793.

23. Ibid.
24. Inc42 Datalabs. (2002). India's Healthtech Landscape in a Post-Covid-19 World. Retrieved October 04, 2020 from www.Inc42.com https://inc42.com/reports/indiahealthtech-landscape-in-a-post-covidworld/ 